\title{
Processo de internacionalização e sistemas adaptativos complexos
}

Rennaly Alves da Silva ${ }^{1 A B}$, Viviane Santos Salazar ${ }^{B}$, e Walter Fernando Araújo de Moraes ${ }^{B}$

A Universidade Federal da Paraíba, UFPB, João Pessoa, PB, Brasil

${ }^{B}$ Universidade Federal de Pernambuco, UFPE, Bananeiras, PE, Brasil

\section{DETALHES DO ARTIGO}

\section{Histórico do artigo:}

Recebido: 15 de março de 2017

Revisado: 02 de junho de 2017

Aceito: 06 de outubro de 2017

Disponível online: 12 de novembro de 2017

Sistema de Revisão "Double Blind Review"

Editor científico:

Diego Pinto

\section{Palavras-chaves:}

Modelo de Uppsala

Sistemas Adaptativos Complexos

Santa Cruz do Capibaribe.

\begin{abstract}
RESUMO
O presente artigo tem como objetivo analisar as características do processo de internacionalização de empresas do polo de Confecções de Santa Cruz do Capibaribe, em Pernambuco, considerando a abordagem dos Sistemas Adaptativos Complexos. São analisados os comportamentos de duas empresas em direção aos mercados externos ao longo do tempo. O método de pesquisa caracteriza-se como qualitativo, com abordagem longitudinal. A estratégia adotada é a de estudo de casos. Foram realizadas entrevistas semiestruturadas, além de observação e pesquisa documental. A análise dos dados é realizada a partir do método de comparação constante, proposto por Merriam (2009). É apresentada a análise cruzada dos casos, que gerou quinze (15) evidências. Entende-se que as empresas em processo de internacionalização podem ser consideradas como Sistemas Adaptativos Complexos.
\end{abstract}

(C) 2017 Internext | ESPM. Todos os direitos reservados!

\section{INTRODUÇÃO}

Os estudos sobre administração, de forma geral, são fundamentados no padrão cartesiano, embasado pelas relações de causa e efeito. No entanto, em decorrência das mudanças ocorridas no mundo dos negócios, a compreensão das relações causais não é mais suficiente para analisar o comportamento das organizações (Morin, 2011), especialmente no que se refere à atuação em mercados internacionais, tendo em vista que envolve uma complexa e difusa estrutura em termos de recursos, competências e influências (Hilal \& Hemais, 2001).

Assume-se que, quanto mais complexos forem os comportamentos, mais as empresas (um tipo de organização) manifestarão flexibilidade adaptativa em relação ao ambiente. As ações adotadas serão aptas a modificar constantemente a empresa em função das mudanças externas, sobretudo das aleatoriedades, das perturbações e dos acontecimentos. Elas serão igualmente capazes de modificar o ambiente, moldá-lo e adaptá-lo (Morin, 2011).

Nesse sentido, o Paradigma da Complexidade apresenta-se como uma forma alternativa e mais abrangente de perceber as relações dentro das próprias organizações e as suas interações com o mercado, admitindo as multiplicidades e incertezas. Dentre as abordagens que defendem essa percepção mais ampla dos fenômenos, em que as organizações passam a ser vistas em um processo de interação constante na tentativa de se auto-organizar e se adaptar ao ambiente, se destaca a abordagem dos Sistemas Adaptativos Complexos - SAC (Kelly \& Allison, 1998). Estas autoras buscam explicar o processo de evolução dos SAC por meio de níveis de

\footnotetext{
${ }^{1}$ Contato do autor: rennaly@hotmail.com
} 
adaptação, que vão desde relacionamentos fechados até redes de relacionamento.

Diante do exposto, este artigo objetiva analisar as características do processo de internacionalização de duas empresas privadas do polo de Confecções de Santa Cruz do Capibaribe, em Pernambuco, considerando a abordagem dos Sistemas Adaptativos Complexos. A escolha do polo de Confecções de Santa Cruz do Capibaribe decorre da sua representatividade não só para o estado de Pernambuco, mas também para a região Nordeste. Identifica-se, ainda, que as atividades de internacionalização têm se tornado uma prática frequente em empresas da região (MDIC, 2016).

\section{FUNDAMENTAÇÃO TEÓRICA}

\subsection{Abordagem Comportamental da Internacionalização}

A abordagem comportamental busca explicar a internacionalização como um processo gradual, no qual o grau de envolvimento com os mercados internacionais aumenta a partir da aquisição de conhecimento experiencial (Johanson \& Vahlne, 1977; Cavusgil, 1984). O U-Model, ou Modelo de Uppsala, é a principal vertente dessa abordagem.

O foco inicial de estudo para o desenvolvimento do Modelo de Uppsala é a empresa individual. De forma geral, se assume que o desenvolvimento das atividades e a solução de possíveis problemas exigem conhecimento sobre o funcionamento do mercado, o que implicaria no comprometimento crescente dos recursos (Johanson \& Vahlne, 1977).

Assim, as empresas começam a exportar para países cuja Distância Psíquica é menor em relação ao país de origem, ou seja, cujos fatores que dificultam ou impedem o fluxo de informações com o mercado são menores (Eriksson et al., 1997). Contudo, a dificuldade na obtenção do conhecimento pode ser um obstáculo para a internacionalização, pois parte essencial desse conhecimento só pode ser obtida mediante experiência (Johanson \& WiedersheimPaul, 1975).

Assim, o curso de ações em direção aos mercados internacionais segue uma cadeia de estabelecimento: inicialmente as atividades de exportação são não regulares, seguidas de exportação por meio de representantes independentes (agentes), do estabelecimento de filiais de vendas e, por fim, das subsidiárias de produção (Johanson \& WiedersheimPaul, 1975; Johanson \& Vahlne, 1977).

Desde a sua publicação, diversos estudiosos se empenharam em avaliar a sua aplicabilidade e sua validade teórica. Em consequência, o trabalho de Johanson e Vahlne (1977) é o mais citado dentre os publicados pelo Journal of International Business. A aplicabilidade do Modelo tem sido comprovada em diversos países: para empresas norteamericanas (Cavusgil, 1984), australianas (Windersheim-Paul, Olson \& Welch, 1978), japonesas (Calof \& Beamish, 1995) e brasileiras (Hilal \& Hemais, 2001). Em outros casos, os conceitos do Modelo não são identificados como congruentes com a prática (Calof \& Beamish, 1995; Welch \& Luostarinen, 1988).

Em trabalho posterior (Johanson \& Vahlne, 2006), os autores seminais de Uppsala sugerem uma série de esclarecimentos sobre a interpretação errônea dada aos seus pressupostos no desenvolvimento de vários estudos. Mesmo assim, os autores reconhecem que o modelo inicial (Johanson \& Vahlne, 1977) possui algumas limitações.

Em resposta às críticas e dando continuidade aos estudos que indicaram tal caminho, a análise do processo de internacionalização é estendida sob a perspectiva dos relacionamentos. Uma forma de analisar as relações entre parceiros na internacionalização seria adotar a perspectiva de tríade, quando comprador, vendedor e intermediário mantêm contato uns com os outros, fazendo com que a relação envolva diretamente as três partes (Havila, Johanson \& Thilenius, 2004).

Não obstante, estas relações são conectadas por redes que as influenciam direta ou indiretamente; sendo que esse aspecto foi negligenciado no modelo inicial (Johanson \& Vahlne, 1977). Posteriormente, a criação de oportunidades foi incluída na discussão e no próprio modelo (Johanson \& Vahlne, 2009), de modo que os relacionamentos da rede proporcionam mais do que o aprendizado, são capazes de tornar a empresa um insider, ou seja, incluí-la na rede de negócios. Uma empresa que não tem uma posição relevante na rede é um outsider, não tendo acesso a informações importantes (Johanson \& Vahlne, 2009).

Mais recentemente, foi incluída a capacidade empreendedora, pois se entende que o empresário que toma as decisões de internacionalização é influenciado por características idiossincráticas, 
sendo a aprendizagem experiencial um fator importante (Schweizer, Vahlne \& Johanson, 2010).

\subsection{Sistemas Adaptativos Complexos}

Entender as organizações (mais especificamente, empresas) enquanto sistemas permite compreender a sua capacidade de aprender e adaptar-se ao ambiente, a partir das informações que conseguem adquirir, o que as torna capazes de responder ativamente ao que ocorre no seu redor. Essa capacidade varia, evoluindo em níveis de complexidade (ou níveis de adaptação). Esses sistemas são definidos como Sistemas Adaptativos Complexos - SAC (Boulding, 1956).

Contribuições relevantes são apresentadas por autores como Kelly e Allison (1998), ao propor o Modelo de Adaptação Evolucionária da Vantagem da Complexidade. No processo de evolução, os SAC passam por níveis de adaptação, relacionados à sua habilidade para identificar as informações e aprender com elas. Essa capacidade denomina-se Vantagem Complexiva. Nesse sentido, são estabelecidos níveis de adaptação (Kelly \& Allison, 1998).

Na Tabela 1, os cinco níveis de adaptação são apresentados com indicações sobre seu alcance, medida e a ênfase da empresa. O alcance significa para onde a atenção está sendo direcionada e varia do foco no agente (nível 1) ao foco na empresa no seu ambiente (nível 5). Quanto à medida, ou seja, a forma como o desempenho da empresa está sendo avaliado, varia entre a produção de dados ao acaso sobre padrões de comportamento desconhecido (nível 1) ao monitoramento dos padrões da empresa e sua coevolução com o ambiente (nível 5). E, por último, a ênfase da empresa varia entre gerentes que tentam comandar e controlar as interações dos agentes, os comportamentos emergentes e os resultados (nível 1) até a coevolução da empresa quantitativamente compreendida interna e externamente refletindo em mudanças incrementais contínuas ou mudanças radicais (nível 5) (Kelly \& Allison, 1998).

Quanto mais elevado o nível de adaptação, mais o foco deixa de ser no indivíduo e passa para o todo organizacional e o seu ambiente. O modelo preconiza, ainda, sete características, denominadas parâmetros, na definição destes níveis (Kelly \& Allison, 1998). São eles: Amplitude, variando do microambiente individual até o macroambiente; Dinamismo, construindo e mantendo padrões de interação e ordem; Aprendizagem, como os indivíduos, equipes e empresa aprendem e se adaptam; Comprometimento, distribuição de poder e nível de autonomia; Interação, resultados das interações do negócio; Autopoiese, grau em que um negócio e suas pessoas podem se sustentar mutuamente; e Sistema emergente, como a empresa vê a si mesma, variando entre um sistema fechado até um sistema aberto.

Tab. 1

Níveis de Adaptação de Auto-organização da Empresa.

\begin{tabular}{|c|c|c|c|c|}
\hline & Nível de Adaptação & Alcance & Medidas & Ênfase da empresa \\
\hline 1 & $\begin{array}{l}\text { Auto-organização } \\
\text { inconsciente }\end{array}$ & Agente & $\begin{array}{l}\text { Produz dados ao acaso sobre } \\
\text { comportamento desconhecido. }\end{array}$ & $\begin{array}{l}\text { Gerentes tentam controlar as interações, } \\
\text { comportamentos e resultados. }\end{array}$ \\
\hline 2 & $\begin{array}{l}\text { Auto-organização } \\
\text { consciente }\end{array}$ & Equipe & $\begin{array}{l}\text { A capacidade da equipe é avaliada } \\
\text { pelo desempenho na execução de } \\
\text { um plano. }\end{array}$ & $\begin{array}{l}\text { Equipes comprometidas e disciplinadas, } \\
\text { comunicação aberta, aprendizado, } \\
\text { comprometimento com os planos de ação } \\
\text { e avaliação de desempenho. }\end{array}$ \\
\hline 3 & Auto-organização guiada & Unidade & $\begin{array}{l}\text { Monitora o desempenho da equipe } \\
\text { em relação aos objetivos em } \\
\text { diversos níveis, articulando micro e } \\
\text { macro emergência. }\end{array}$ & $\begin{array}{l}\text { Equipes locais comprometidas e } \\
\text { disciplinadas propagando experiências de } \\
\text { sucesso, entrelaçando padrões através de } \\
\text { unidades maiores em rede dentro do } \\
\text { contexto ambiental. }\end{array}$ \\
\hline 4 & $\begin{array}{l}\text { Auto-organização guiada } \\
\text { quantitativamente }\end{array}$ & Empresa & $\begin{array}{l}\text { Modelos e análises baseados em } \\
\text { análises estatísticas. }\end{array}$ & $\begin{array}{l}\text { Empresa utiliza estatística para entender, } \\
\text { estabilizar, e prever tendências na rede } \\
\text { de agentes e resultados emergentes. }\end{array}$ \\
\hline 5 & Autopoiese Consciente & $\begin{array}{l}\text { Empresa no } \\
\text { seu ambiente }\end{array}$ & $\begin{array}{l}\text { Monitora padrões na empresa e sua } \\
\text { coevolução com o ambiente. }\end{array}$ & $\begin{array}{l}\text { A co-evolução da empresa é } \\
\text { qualitativamente compreendida interna e } \\
\text { externamente refletindo em mudanças } \\
\text { incrementais ou radicais. }\end{array}$ \\
\hline
\end{tabular}

Fonte: Adaptado de Kelly, S. \& Allison, M. A. (1998, p.112). The complexity advantage: how the science of complexity can help your business achieve peak performance. New York. 


\subsection{As Empresas em Processo de Internacionalização como Sistemas Adaptativos Complexos}

Críticas direcionadas ao modelo de Uppsala referemse à sua limitação na capacidade de explicar as diversas formas possíveis de internacionalização que são capazes de reduzir ou eliminar o gradualismo proposto pelo Modelo. A integração da evolução do modelo de Uppsala, desde 1975 até 2010, com a abordagem dos Sistemas Adaptativos Complexos, pode contribuir para a compreensão de como as empresas se adaptam para atuar de formas tão distintas em mercados diversos. Isso porque a evolução do modelo de Uppsala parece acompanhar os níveis de evolução da complexidade. O foco do modelo avança desde o indivíduo até a empresa e seu ambiente (Johanson \& Vahlne, 1977; Johanson \& Vahlne, 2009). Essa evolução se assemelha ao progresso de consciência percorrido nos níveis de adaptação da complexidade, que variam desde relacionamentos fechados até redes de relacionamento (Kelly \& Allison, 1998).

Inicialmente, o fator considerado fundamental para o processo de internacionalização, tanto com relação à escolha do mercado em que se pretende atuar quanto ao modo de entrada, é a Distância Psíquica (Johanson \& Wiedersheim-Paul, 1975; Johanson \& Vahlne, 1977). Essa percepção evidencia a empresa entendida no modelo como pertencendo ao nível "Auto-organização Inconsciente", partindo do entendimento de que havia competividade entre os agentes e entre as empresas, com compartilhamento limitado de informações, comprometimento superficial - principalmente em decorrência do gradualismo - e preocupação, sobretudo, com os resultados.

Por sua vez, com a evolução para a perspectiva das redes de relacionamentos, percebe-se que o Modelo do Processo de Internacionalização apresenta-se em direção à "Autopoiese Consciente", pois se admite a existência da interação colaborativa entre os agentes $e$ as empresas, com o compartilhamento de informações e a preocupação não apenas com os resultados diretos, mas também com forma de obtenção dos resultados. Isso se torna ainda mais perceptível com o reconhecimento do papel do empreendedor nesse processo (Schweizer, Vahlne \& Johanson, 2010), pois há evidências de que o agente tem consciência da sua atribuição enquanto participante da empresa situada em um ambiente dinâmico.

Diante dessa relação, seria plausível presumir que a decisão da escolha dos mercados internacionais em que se pretende atuar, bem como do modo de entrada, devem levar em consideração não apenas o nível de conhecimento que a empresa possui sobre esses mercados, conforme foi demonstrado com a evolução do Modelo de Uppsala, mas também o nível de adaptação da complexidade, ou seja, a capacidade da organização de se adaptar à realidade do mercado externo. Assim, pode-se esperar que quanto maior o nível de evolução da complexidade, menor será a importância atribuída ao conhecimento na escolha dos mercados externos ou na escolha do modo de atuação nestes mercados.

Isso pode ser verdadeiro quando se assume que, se a empresa é capaz de se adaptar com maior facilidade ao mercado externo, estabelecendo relações pautadas na confiança, o que reduz os efeitos da incerteza e do oportunismo, o seu comprometimento com aquele mercado será maior. E, possivelmente, tal comprometimento ocorrerá de forma menos gradual do que nos casos em que a sua capacidade de adaptação ao mercado é limitada, não havendo a colaboração ou troca de informações relevantes com as empresas estrangeiras.

Assim, se a empresa possui maior capacidade de adaptação aos mercados, a sua escolha dos mercados externos e do modo de atuação poderá ser pautada em outros aspectos, que não apenas a Distância Psíquica ou o nível de conhecimento. Pode-se, então, levar em consideração o nível de rentabilidade esperado ou retorno sobre o investimento. Todavia, se a empresa tiver pouca capacidade adaptativa (o que envolve a sua capacidade de colaboração e compartilhamento de informações) a sua escolha permanecerá pautada apenas no seu grau de conhecimento e nas proximidades psíquicas.

Seguindo essa lógica, também é presumível que o nível mais elevado de complexidade nas empresas, ou seja, a existência de uma maior Vantagem Complexiva, também tenderá a ser maior a sua capacidade de identificar as oportunidades e ameaças dos mercados internacionais. Isso porque as empresas que possuem maior nível de evolução da complexidade são as que buscam constantemente a adaptação competitiva, possuindo um comportamento atento e pronto para mudança, 
sendo mais preparadas para auto-eco-organização (Kelly \& Allison, 1998; Morin, 2011).

Além disso, a própria percepção dessas oportunidades e ameaças não é vista pelo modelo de Uppsala como algo buscado pelas empresas, mas como algo proporcionado pela sua prontidão para reconhecer o valor das informações e ideias, bem como decorrente da capacidade do empreendedor de transformar ameaças em oportunidades ou, até mesmo, de criá-las (Schweizer, Vahlne \& Johanson, 2010). Nesse sentido, pode-se supor que empresas com nível de adaptação complexiva mais elevado seriam capazes de identificar mais facilmente as oportunidades e ameaças nos mercados internacionais.

Essa necessidade de aquisição do conhecimento de forma experiencial, restrita à atuação no mercado específico, inclusive para capacidade de percepção das oportunidades e ameaças, poderia ser substituída pela participação em redes de relacionamento ou pela contratação de alguém que detenha esse conhecimento (Johanson \& Vahlne, 1977, 2009). Essa evolução também parece estar de acordo com os níveis de complexidade ou de adaptação, pois a necessidade de conhecimento experiencial está associada às empresas com as características mais próximas às do nível "Autoorganização Inconsciente", enquanto as que são capazes de substituir tal conhecimento com a sua participação em redes de relacionamentos possuem as características referentes ao nível de "Autopoiese Consciente", ou dos níveis mais próximos deste. Desse modo, entende-se que empresas com nível de adaptação complexiva mais elevado podem mais facilmente conseguir se tornar insiders em redes de negócios.

Nesse sentido, argumenta-se que as empresas estão dispostas a constituir relacionamentos de negócio apenas com aquelas capazes de cooperar e compartilhar informações relevantes, sendo estas exigências características de empresas com elevado nível adaptação complexiva. Assim, espera-se que empresas que tenham maior nível de evolução da complexidade estejam mais aptas a atuar em mercados internacionais.

\section{PROCEDIMENTOS METODOLÓGICOS}

Na realização da pesquisa, é adotada a perspectiva de processo longitudinal (Pettigrew, 1987), em que há uma série temporal de eventos críticos ou estados
(Melin, 1992), com caráter retrospectivo, ex-post facto - no período que compreende desde o início das atividades nos mercados externos até o ano de 2012 (Matos \& Vieira, 2001). Por eventos críticos entende-se: "fatos, situações e decisões vivenciadas e/ou tomadas pela empresa que impactaram ou desencadearam em mudanças" durante o processo de internacionalização (Sousa \& Freitas, 2012, p. 12).

Desse modo, a análise das características do Processo de Internacionalização das empresas ocorreu a partir da busca por avaliar de que formas a empresa se comporta em determinados eventos considerados críticos para esse processo. Para esses eventos críticos, foram avaliados os níveis de complexidade presentes no comportamento das empresas.

Para isto, adota-se uma abordagem qualitativa (Denzin \& Lincoln, 2005). Com relação à estratégia de pesquisa, opta-se pelo estudo de caso, que também pode ser utilizado para conduzir um estudo com mais de um caso, comumente chamado de múltiplo ou cross-case (Merriam, 2009).

A análise preliminar do site do Ministério do Desenvolvimento, Indústria e Comércio - MDIC revela que, entre os anos de 2001 e 2011, treze (13) empresas do polo de confecções de Santa Cruz do Capibaribe exportaram até US\$ 1 milhão. Assim, o critério de "oportunidade planejada" (Pettigrew, 1987, p. 274) foi adotado para escolha das duas empresas em estudo. O nome das empresas selecionadas foi substituído por nomes fictícios. São elas: 'Moda Praia' e 'Surf Wear'.

Com relação à escolha dos entrevistados, ocorreu de forma não probabilística (Merriam, 2009), com a técnica de seleção por conveniência (Patton, 2001; Merriam, 2009). Foram entrevistados os membros da direção - aqueles responsáveis pelos processos de internacionalização das empresas - e outras pessoas que estivessem acompanhando o processo desde o início. Assim, a coleta das informações ocorreu por meio da realização de nove (9) entrevistas semiestruturadas, observação não participante e pesquisa documental. Os dados provenientes foram analisados por meio do Método de Comparação Constante (Merriam, 2009). Para auxiliar na análise dos dados, foi utilizada a versão 6.0 do software Atlas.ti.

Foi realizada a análise cruzada dos casos, de modo a tornar possível perceber aspectos semelhantes ou

Internext | São Paulo, v.12, n. 3, p. 61-76, set./dez. 2017 
divergentes entre os casos que indiquem padrões de comportamentos (Merriam, 2009). Estes padrões de são confrontados com os elementos teóricos abordados.

\subsection{Os casos}

A Moda Praia iniciou suas atividades em Santa Cruz do Capibaribe no ano de 1980. No presente, dispõe de um fábrica e atende ao público com duas lojas. A empresa conta com uma equipe de 35 colaboradores. Porém, diretamente envolvidos no processo de internacionalização são apenas a proprietária, sua filha e o gerente.

A Surf Wear foi fundada em 1996 na mesma cidade. Atua no ramo de confecções e conta com 13 representantes comerciais, atendendo 21 estados brasileiros. Possui 5 lojas que empregam 194 colaboradores, além dos 210 que atuam na fábrica. 0 seu processo de internacionalização também envolve poucas pessoas. Inicialmente foi entrevistada a secretária da diretoria, o diretor proprietário e o gerente administrativo, que indicaram outras três pessoas envolvidas.

A seguir, será apresentada a análise dos resultados, com a descrição das características de cada evento considerado crítico para o processo de internacionalização das empresas.

\section{ANÁLISE DOS RESULTADOS}

\subsection{O processo de Internacionalização}

A partir da análise dos casos, foi possível perceber aspectos semelhantes e divergentes. Primeiramente, percebe-se que não houve interrupção no processo de internacionalização no caso da Moda Praia. As exportações continuaram ocorrendo desde 2004. Além disso, houve menos mudanças no processo, ou seja, ocorreram menos eventos críticos, influenciadores de mudanças - apenas dois: 1) participação na rodada de negócios realizada em Recife, no ano de 2004; e 2) mudança de um filho da proprietária para a Espanha, em 2005, como pode ser observado na Figura 1.

Por outro lado, a Surf Wear tem um processo de internacionalização que foi interrompido. A empresa exportou entre os anos de 2004 e 2006 e, mais recentemente, desde 2010, começou a importar. Assim, percebe-se que a empresa interrompeu durante 4 anos as suas atividades de internacionalização, conforme indica a linha pontilhada na parte inferior da Figura 1. Além disso, vivenciou quatro eventos críticos, que foram: 1) participação na rodada de negócios em Fortaleza CE, em 2004; 2) indicação feita por um ex-design da empresa, no mesmo ano, que resultou na parceria com uma empresa portuguesa; 3 ) decisão por cessar as atividades de exportação, em 2006; e, por último, 4) participação na feira de Cantão, na China, no ano de 2010. Todos os eventos críticos são detalhados a seguir.

Apesar dessas diferenças, o primeiro evento crítico para o processo de internacionalização das duas empresas ocorreu em 2004, possuindo características muito semelhantes. Estas são decorrentes da influência exercida pela atuação dos órgãos de fomento locais, que, nesse período, se mostravam bastante atuantes na promoção de rodadas de negócios internacionais e na inclusão das empresas locais em eventos realizados por todo o Brasil e no exterior. Assim, a primeira experiência de exportação para os dois casos em estudo ocorreu em função da participação das empresas em duas rodadas de negócios internacionais, ocorridas em Recife-PE e Fortaleza-CE.

As características dos processos de internacionalização das empresas relacionados ao primeiro evento crítco podem ser observadas na

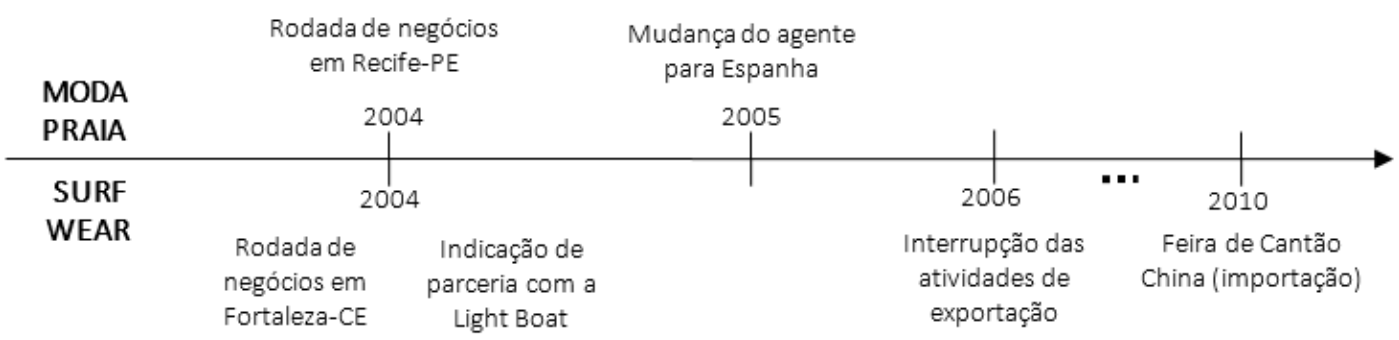

Fig. 1

Eventos críticos para o processo de internacionalização.

Fonte: Dados da pesquisa (2012) 


\begin{tabular}{|c|c|}
\hline \multirow{9}{*}{$\begin{array}{l}\text { Rodada de negócios } \\
\text { em Recife-PE } \\
\text { exportaçäo para a França } \\
2004\end{array}$} & CARACTERÍSTICAS: \\
\hline & Conhecimento do mercado: Não havia \\
\hline & Conhecimento dos processos: Não havia \\
\hline & Distância Psíquica: Elevada \\
\hline & Escolha do mercado: Não houve, mas surgiu como oportunidade \\
\hline & $\begin{array}{l}\text { Influência das Redes de Relacionamento: A oportunidade foi proporcionada pelos órgãos de } \\
\text { fomento }\end{array}$ \\
\hline & Modo de entrada: Por intermédio de um agente de exportação \\
\hline & Modo de atuação: Não houve continuidade de exportação para o mercado \\
\hline & Papel do empreendedor. A empreendedora tem papel importante no mercado local \\
\hline \multirow{6}{*}{$\begin{array}{c}2004 \\
\text { Rodada de negócios em } \\
\text { Fortaleza-CE exportação } \\
\text { para Portugal }\end{array}$} & CARACTERÍSTICAS: \\
\hline & $\begin{array}{l}\text { Conhecimento do mercado O proprietário conhecia o país - mas nunca havia negociado no } \\
\text { mercado }\end{array}$ \\
\hline & Conhecimento dos processos: Não havia \\
\hline & Distância Psíquica: Reduzida \\
\hline & Escolha do mercado: Não houve, mas surgiu como oportunidade \\
\hline & $\begin{array}{l}\text { Influência das Redes de Relacionamento: A oportunidade foi proporcionada pelos órgãos de } \\
\text { fomento }\end{array}$ \\
\hline SURF & Modo de entrada: Por intermédio de um agente de exportação \\
\hline WEAR & $\begin{array}{l}\text { Modo de atuação: Houve continuidade das exportações para o mercado até } 2006 \\
\text { Papel do empreendedor. Possui visão de internacionalização, além da sua importância no } \\
\text { mercado local }\end{array}$ \\
\hline
\end{tabular}

Fig. 2

Primeiro evento crítico para o processo de internacionalização.

Fonte: Dados da pesquisa (2012)

Figura 2. A Moda Praia participou de uma rodada de negócios em Recife, Pernambuco, o que resultou na realização da primeira exportação da empresa para um cliente francês. No mesmo período, a Surf Wear participou de uma rodada de negócios em Fortaleza, Ceará, o que precedeu na exportação para Portugal. As duas empresas ainda não possuíam conhecimento sobre os processos de exportação. No entanto, o proprietário da Surf Wear já conhecia o país e desempenhou um papel importante em função da sua percepção sobre os mercados externos; enquanto a proprietária da Moda Praia, assim como nenhum dos seus colaboradores, conhecia o mercado francês.

De qualquer modo, essas diferenças não exerceram um impacto considerável com relação à escolha pelo modo de entrada nos mercados externos ou na própria escolha pelos mercados de atuação. Essas escolhas podem ter sido influenciadas pelas suas experiências nos mercados locais, pois antes de começar a atuar em outros países, as duas empresas já atuavam em outros estados, como sugerem estudos anteriores (Windersheim-Paul, Olson \& Welch, 1978). Tem-se, então, a seguinte evidência:

Evidência 1: As empresas, antes de começarem a atuar em outros países, atuam em outros estados nacionais.

Ademais, com relação ao modo de entrada nos mercados externos, foi evidenciado que as duas empresas começaram atuando por intermédio de agentes de exportação. De modo semelhante, as suas atuações interestaduais se restringiam aos representantes de vendas ou clientes que revendiam os produtos em outros estados, não havendo subsidiárias de vendas ou de produção instaladas em qualquer estado que não Pernambuco. Isso indica que as empresas podem ter estendido o seu modo de atuação nos mercados locais para os mercados externos, sugerindo que:

Evidência 2: 0 modo de atuação interestadual pode influenciar a escolha pelo modo de entrada em outros países.

Com relação à escolha pelos mercados, tal decisão não ocorreu em nenhum dos casos. O Modelo de Uppsala sugere que as empresas escolhem exportar para países dos quais já possua conhecimento ou que tenha menor Distância Psíquica com relação ao país de origem (Johanson \& Vahlne, 1977). Contudo, sabe-se que não houve escolha deliberada, mas que estes mercados surgiram como oportunidades de negócios nas rodadas internacionais que foram apresentadas às empresas pelos agentes de exportação, que já conheciam e negociavam com os mercados externos, indicando que:

Evidência 3: As empresas começam a atuar nos mercados externos por intermédio de agentes independentes, não obstante a Distância Psíquica.

Por sua vez, as diferenças entre os casos quanto à existência ou não de conhecimento prévio sobre os mercados externos não tiveram impacto sobre a escolha do primeiro país de exportação. As 


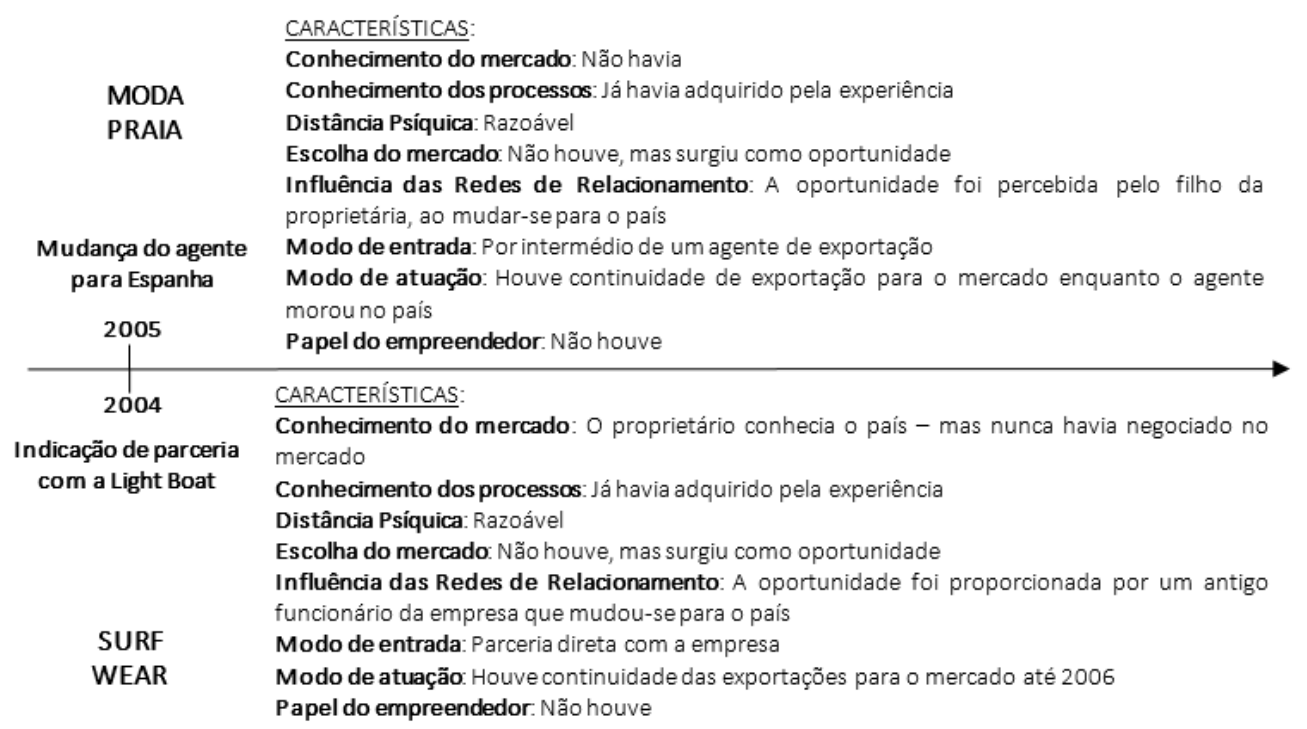

Fig. 3

Segundo evento crítico para o processo de internacionalização. Fonte: Dados da pesquisa (2012).

dificuldades impostas pela ausência de conhecimento puderam ser superadas, no momento de escolha do mercado, pela participação do agente de exportação, que intermediou as negociações. Isso sugere que:

Evidência 4: A necessidade de conhecimento para a escolha do mercado externo pode ser substituída pelo conhecimento dos agentes de exportação.

Entretanto, essas diferenças quanto ao conhecimento das empresas sobre os mercados externos podem ter exercido uma influência importante no que diz respeito à sua continuidade da atuação em tais mercados. A Moda Praia, que não conhecia o mercado francês antes de iniciar a exportação, apesar de ter visitado o país posteriomenmte para participar de uma rodada de negócios, não conseguiu permanecer atuando no mesmo; enquanto a Surf Wear, que já conhecia o mercado português antes de iniciar as atividades de exportação, conseguiu se manter no mercado, o que indica que:

Evidência 5: O conhecimento prévio sobre os mercados externos pode facilitar a continuidade de atuação da empresa nestes mercados.

Além disso, outro aspecto importante para o processo de internacionalização - de acordo como Modelo de Uppsala (Johanson \& Vahlne, 1977) - que se apresenta de forma muito distinta para as empresas é a Distância Psíquica do país de exportação com relação ao mercado local. O fato de a Moda Praia não ter dado continuidade às exportações para a França - país mais distante psiquicamente -, enquanto a Surf Wear continuou exportando para Portugal, inclusive envolvendo-se mais com o mercado - quando começou a terceirizar os produtos da Light Boat -, pode indicar que a Distância Psíquica, de fato, exerce influência sobre a possibilidade de envolvimento da empresa com os mercados externos, embora não tenha exercido impacto na escolha dos mercados. Assim:

Evidência 6: A Distância Psíquica pode não exercer influência sobre a escolha dos mercados, mas sobre a continuidade de atuação da empresa no mercado externo.

Isso ocorre, especialmente, quando as dificuldades impostas pela Distância Psíquica são superadas por intermédio da atuação dos agentes de exportação ou pela contribuição das redes de relacionamentos, que são capazes de inserir as empresas nos mercados externos e de facilitar o fluxo de informações entre os mercados.

A influência das redes de relacionamentos é mais evidente no segundo evento considerado crítico para o processo de internacionalização das empresas. Neste caso, percebe-se a existência de diversas similaridades entre os casos analisados: as Distâncias Psíquicas entre os mercados eram semelhantes, consideradas baixas; as duas empresas possuíam conhecimento sobre os processos de exportação; não houve influência direta do empreendedor, mas a exportação ocorreu a partir do surgimento de oportunidades; e, mais uma vez, não houve escolha pelos mercados de atuação, mas estes surgiram em

Internext | São Paulo, v.12, n. 3, p. 61-76, set./dez. 2017 


\begin{tabular}{|c|c|}
\hline & CARACTERÍSTICAS: \\
\hline \multirow{7}{*}{$\begin{array}{c}2006 \\
\text { Interrupção das } \\
\text { atividades de } \\
\text { exportação }\end{array}$} & 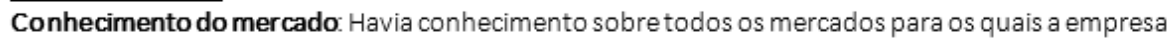 \\
\hline & exportava \\
\hline & Conhecimento dos processos: Já havia adquirido pela experiência \\
\hline & Distância Psíquica: Razoável para todos os países para os quais exportava \\
\hline & Escolha do mercado: Não houve, todos surgiram como oportunidades \\
\hline & Influência das Redes de Relacionamento: Importante para todas as exportações \\
\hline & Modo de entrada: Por agente de exportação ou parceria direta com a empresa \\
\hline SURF & Modo de atuação: Houve continuidade das exportações para todos os mercados até 2006 \\
\hline WEAR & $\begin{array}{l}\text { Papel do empreendedor: Importante com a visão de internacionalização, além da sua importância } \\
\text { no mercado local }\end{array}$ \\
\hline
\end{tabular}

Fig. 4

Terceiro evento crítico para o processo de internacionalização

Fonte: Dados da pesquisa (2012)

função do conhecimento que os agentes externos possuíam. Esta última característica indica que a falta de conhecimento, novamente, pôde ser compensada pela atuação dos agentes. As características dos eventos são apresentadas na Figura 3.

Entretanto, também há divergências. Percebe-se que a relação da Moda Praia com o agente de exportação se mostrou ser bem mais forte do que a relação que a Surf Wear possuía com o seu representante. Isso teve um impacto importante para o processo de internacionalizaçao das empresas: as negociações entre da Moda Praia e os clientes espanhóis se tornaram dependentes da atuação do agente, de modo que, quando o agente não pôde mais intermediá-las, a empresa perdeu o contato com estes clientes; por outro lado, o agente da Surf Wear serviu apenas como um facilitador do contato entre a empresa e o seu cliente, a Light Boat, fazendo com que a relação entre as empresas pudesse ser estabelecida e mantida independente da permanência ou não do agente de exportação, o que caracteriza uma tríade (Havila, Johanson \& Thilenius, 2004).

Nesse sentido, evidencia-se que essa substituição da necessidade de conhecimento por parte da empresa sobre os mercados externos por meio da atuação dos agentes de exportação exerce uma influência importante sobre a escolha dos mercados de atuação e para facilitar o acesso da empresa aos mesmos. Entretanto, quando se trata da continuidade do relacionamento, a atuação por intermédio destes agentes pode limitar a capacidade da empresa de permanecer no mercado, tornando-a dependente de tais agentes, ou seja:
Evidência 7: A atuação nos mercados externos por intermédio dos agentes de exportação pode tornar as relações da empresa com estes mercados dependentes dos agentes.

Assim, esses dois eventos críticos para cada empresa foram considerados os mais importantes para as mudanças ocorridas nas suas atividades de exportação. 0 comportamento de internacionalziação da Moda Praia permanece apresentando o padrão de características exposto, não havendo mundaças quanto à forma de atuação, à escolha dos mercados, ao modo como adquire os conhecimentos, ou qualquer outro aspecto.

Todavia, em 2006, a Surf Wear resolveu encerrar suas atividades de exportação, o que caracteriza outro marco importante para o seu processo de internacionalização, conforme demonstrado na Figura 4.

Contrariando as lógicas subjacentes ao Modelo de Uppsala, a Surf Wear apresentava características propícias para dar continuidade ao seu processo de internacionalização, inclusive, para evoluir na Cadeia de Estabelecimento, passando, por exemplo, da atuação por meio dos agentes independentes para a atuação por intermédio de subsidiária de vendas possuía conhecimento sobre os mercados e sobre os processos; atuava em países com baixa distância psíquica; e o empreendedor, assim como a rede de relacionamentos, realizavam papéis importantes, que contribuíam para o sucesso da empresa nos mercados externos -, mas a empresa preferiu interromper suas atividades de exportação.

Como justificativa para a interrupção de tais atividades, a empresa aponta o cumprimento da sua estratégia: se preparar para atuar nos mercados externos apenas quando estiver totalmente 
fortalecida no mercado local. Inicialmente, o seu objetivo era obter conhecimento sobre os processos de exportação para não estar leiga no momento em que estas atividades pudessem se tornar imprescindíveis para a manutenção do seu desempenho, tendo em vista que havia um movimento das empresas locais para os mercados externos incentivado pelos agentes de fomento.

Não obstante, quando adquiriu o conhecimento que necessitava, a Surf Wear percebeu que a atuação nos mercados externos impedia a execução da sua estratégia para o mercado local: se fortalecer e expandir a marca no Brasil. Isso fez com que a empresa decidisse por interromper a sua atuação naqueles mercados. Esse comportamento indica que os aspectos internos, como a estratégia da empresa e suas capacidades, podem influenciar igualmente o processo de internacionalização das empresas, conforme evidenciado por diversos críticos ao Modelo de Uppsala, (Calof \& Beamish, 1995; Welch \& Luostarinen, 1988). Assim, percebe-se que:

Evidência 8: Os aspectos internos podem influenciar o processo de internacionalização das empresas tanto quanto os aspectos externos.

Por fim, o evento que resulta na maior diferença entre os processos de internacionalização da Moda Praia e da Surf Wear é a participação desta empresa na Feira de Cantão, na China, em 2010. Enquanto a Moda Praia permaneceu realizando exportações que possuíam as mesmas características, a Surf Wear interrompeu suas atividades de exportação em 2006 e, em 2010, retomou o processo, mas, ao invés de exportar, a empresa começou a importar da China.

Ao apsentar os conceitos básicos sobre negócios internacionais, Cavusgil, Knight e Riesenberger (2017) assumem que a internacionalização é "a tendência das empresas de aprofundar suas atividades comerciais internacionais" e que o comércio internacional envolve "o intercâmbio de produtos e serviços através das fronteiras nacionais, normalmente por meio da exportação e importação" (Cavusgil, Knight \& Riesenberger,2017, p. 5). Nesse sentido, considera-se, para fins deste estudo, que o processo de internacionalização das empresas, ou seja, as suas atividades comerciais internacionais, compreende tembém as atividades de importação, uma vez que estas permitem obter conhecimentos sobre mercados e processos ligados ao comércio internacional.

Este evento apresenta características semelhantes àquelas já identifcadas nos eventos da empresa que se referem às exportações, como a existência de conhecimento sobre os processos, a influência das redes de relacionamento, o modo de entrada no mercado e o papel do empreendedor. Todavia, várias outras características distinguem este dos demais eventos críticos da própria empresa, como a ausência de conhecimento sobre o mercado chinês, a própria escolha pelo mercado e a elevada Distância Psíquica, como pode ser observado na Figura 5.

Estas três características se apresentam de forma relacionada: embora a empresa não conhecesse o mercado chinês e mesmo que esse mercado apresentasse elevada Distância Psíquica com relação ao país de origem, e empresa o escolheu para realizar as importações, levando em consideração os baixos preços praticados pelos fornecedores chineses. Esse comportamento não está em consonância com a premissa do Modelo de Uppsala de que as empresas escolhem os mercados em função do conhecimento que possuem sobre os mesmos ou em decorrência da Distância Psíquica existente (Johanson \& Vahlne, $1975,1977)$. Assim, ao invés de buscar aumentar o seu comprometimento com os mercados que já

\begin{tabular}{|c|c|}
\hline 1 & CARACTERÍSTICAS: \\
\hline 2010 & Conhecimento do mercado: Não havia \\
\hline Feira de Cantão & Conhecimento dos processos: Já havia adquirido pela experiência \\
\hline \multirow{4}{*}{ China (importação) } & Distância Psíquica: Elevada \\
\hline & Escolha do mercado: Em função dos preços \\
\hline & $\begin{array}{l}\text { Influência das Redes de Relacionamento: A oportunidade foi proporcionada pelos órgãos de } \\
\text { fomento e a indicação feita por um agente de importação }\end{array}$ \\
\hline & Modo de entrada: Parceria direta com a empresa \\
\hline SURF & Modo de atuação: As importações permanecem até hoje, sem pretensão de interromper \\
\hline WEAR & $\begin{array}{l}\text { Papel do empreendedor: Importante com a visão de internacionalização, além da sua } \\
\text { importância no mercado local }\end{array}$ \\
\hline
\end{tabular}

Fig. 5

Quarto evento crítico para o processo de internacionalização.

Fonte: Dados da pesquisa (2012).

Internext | São Paulo, v.12, n. 3, p. 61-76, set./dez. 2017 
conhecia, a empresa buscou um novo mercado, desconhecido e distante psiquicamente, para dar continuidade ao seu processo de internacionalização.

Nesse sentido, percebe-se que a empresa não considerou estes aspectos, apresentados como relevantes no Modelo de Uppsala, mas apenas os benefícios de preço proporcionados pela escolha. As elevadas diferenças culturais, de idioma e com relação à forma de fazer negócios, por exemplo, puderam ser superadas com o auxílio dos agentes de importação - Evidência 4. Mesmo assim, a empresa mantém contato diretamente com o fornecedor, não sendo totalmente dependente deste agente - o que reduz os efeitos da Evidência 7. Outro aspecto importante para que houvesse a escolha por um mercado tão distante psíquicamente, foi o fato de a empresa já estar familiarizada com os processos de exportação, possuíndo conhecimentos sobre transações internacionais. Isso pode significar que:

Evidência 9: O conhecimento sobre os processos pode ser mais importante do que o conhecimento sobre os mercados para a escolha do mercado de atuação.

A seguir, é apresentada a análise cruzada dos casos com relação aos seus níveis de adaptação complexiva.

\subsection{Níveis de Adaptação Complexiva}

Os padrões de comportamento das empresas demonstram que elas se encontram localizadas em extremos quanto aos seus níveis de adaptação complexiva, o que pode ser percebido no continuum apresentado na Figura 6.

Percebe-se que o comportamento da Moda Praia indica que há mais interação competitiva, compartilhamento de informações limitado, comprometimento superficial e coevolução desarticulada, características de empresas que se encontram no nível 1 de adaptação complexiva Auto-organização Insconsciente. Neste nível, as atividades da empresa são desenvolvidas independente da compreensão dos agentes ou das suas intenções, pois a gerência busca controlar suas ações, mantendo o foco nos resultados. Contudo, a empresa também apresenta comportamentos referentes ao nível 2 - Auto-organização Insconsciente, como, o compartilhamento de informações e conhecimentos com alguns colegas que atuam nas mesmas equipes de trabalho. Os agentes passam a entender os meios pelos quais os resultados podem ser buscados (Kelly \& Allison, 1997).

Por sua vez, no caso da Surf Wear, percebe-se que há padrões de comportamento mais próximos daqueles desejados para que a empresa alcance a Vantagem Complexiva - interação colaborativa, compartilhamento de informações de forma aberta e completa, comprometimento profundo e coevolução articulada. Evidenciou-se que a empresa se encontra no nível 5 de adaptação complexiva - Autopoiese -, em que a melhoria das atividades se torna um processo contínuo. Os colaboradores assumem um comportamento atento, capaz de identificar as necessidades de mudança e de evoluir em conjunto com a empresa. O conhecimento é resultado das experiências anteriores (Kelly \& Allison, 1997). Porém, ainda possui alguns comportamentos referentes ao nível 4 - Auto-organização Guiada Quantitativamente - como monitorar as variações do ambiente em vez de antecipar-se (Kelly \& Allison, 1997).

Assim, percebe-se quão distintos são os comportamentos das empresas com relação às suas capacidades de identificar informações e aprender

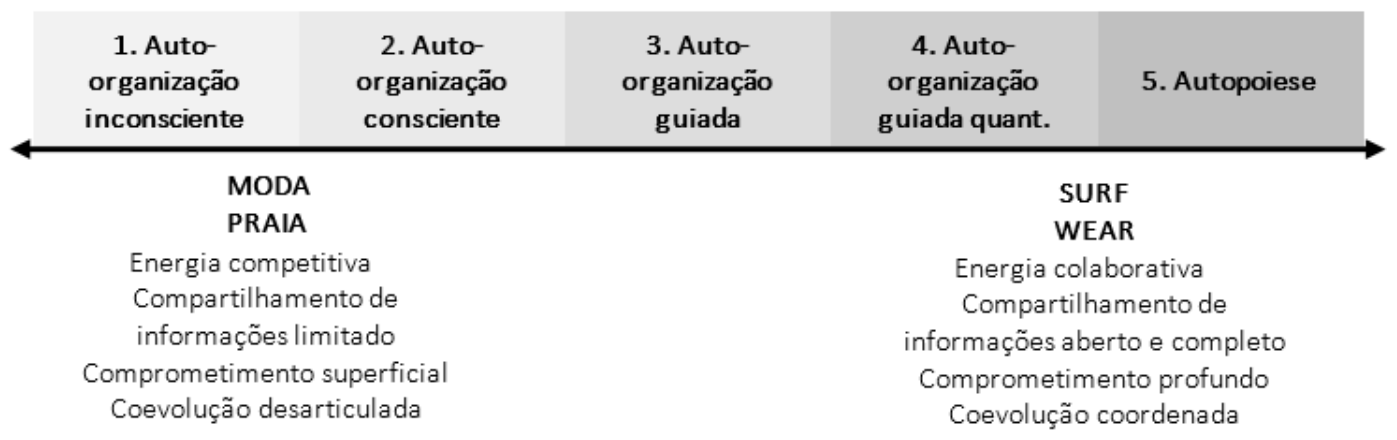

Fig. 6

Nível de adaptação complexiva.

Fonte: Dados da pesquisa (2012) 
com elas, de se adaptar de forma competitiva e de se auto-organizar. As evidências indicam que a Surf Wear possui considerável Vantagem Complexiva com relação à Moda Praia, ou seja, a Surf Wear é mais capaz de se adaptar a ambientes instáveis, por exemplo.

\subsection{Empresas em Processo de Internacionalização podem ser consideradas Sistemas Adaptativos Complexos?}

Sabe-se que os dois casos analisados se apresentam em situações opostas quanto ao nível de adaptação complexiva - Moda Praia no nível 1 e Surf Wear no nível 5. Além disso, foi evidenciado que o proprietário da Surf Wear conhecia praticamente todos os países de exportação, enquanto a Moda Praia não conhecia nenhum deles. Entretanto, sabe-se também que nenhuma das empresas escolheu os mercados de exportação, o que pode ser observado na Evidência 4 - "A necessidade de conhecimento para a escolha do mercado pode ser substituída pelo conhecimento dos agentes de exportação".

Assim, independente do nível de complexidade, o conhecimento sobre os mercados ou sua ausência não exerceu influência com relação à escolha dos países de exportação. Porém, foi possível identificar que a Moda Praia permaneceu adotando este comportamento de não escolha dos mercados, o que continua ocorrendo. Por sua vez, a Surf Wear, após obter experiência, passou a escolher o mercado de atuação - no caso da importação da China -, do qual não possuía conhecimento.

Desse modo, acredita-se que, além da importância do nível de adaptação complexiva da empresa, os conhecimentos adquiridos sobre os processos de exportação também influenciaram a escolha posterior do mercado. Nessa perspectiva, é possível entender que ao escolher os mercados externos de atuação, as empresas que possuem maior o nível de evolução da complexidade, tendem a atribuir menor importância à necessidade de conhecimentos sobre estes mercados. Isso ocorre especialmente quando as mesmas possuem conhecimento sobre os processos (ERIKSSON et. al., 1997), ou seja, conhecimentos experienciais sobre os trâmites necessários para atuar nos mercados internacionais, o que indica que:
Evidência 10: Na escolha dos mercados externos de atuação, quanto maior o nível de evolução da complexidade, menor será a importância atribuída aos conhecimentos sobre estes mercados, desde que a empresa possua conhecimentos sobre os processos.

Ademais, evidenciou-se que, em função da capacidade de adaptação da Surf Wear aos mercados externos - característica do seu nível de adaptação da complexidade - a escolha dos mercados externos pode ser pautada em outros aspectos, que não apenas no nível de conhecimento ou na Distância Psíquica, tais como o nível de rentabilidade esperado ou retorno sobre o investimento. Isso fica evidente quando a Surf Wear opta por terceirizar produtos da China com base nos preços oferecidos pelos fornecedores deste país, embora não conhecesse o mercado e houvesse considerável Distância Psíquica com relação ao mercado local. Assim, pode-se acrescentar que:

Evidência 11: Quanto maior o nível de evolução da complexidade, menos importante será a Distância Psíquica na escolha dos mercados externos.

Além disso, espera-se que a escolha pelo modo de atuação também possa ser influenciada pelo nível de complexidade da empresa e não apenas pelos fatores que propõe o Modelo de Uppsala - conhecimento sobre os mercados e Distância Psíquica. Nesse sentido, apesar de as duas empresas atuarem por intermédio de agentes de exportação, foi evidenciado que a Moda Praia, que possui o menor nível de adaptação complexiva, é mais dependente da atuação dos agentes de exportação do que a Surf Wear.

Ao contrário, percebe-se que a Surf Wear, embora tenha tido oportunidades semelhantes de atuação nos mercados externos, como pode ser percebido nos dois primeiros eventos críticos para as duas empresas, assumiu um comportamento de internacionalização menos dependente dos agentes, que, muitas vezes, serviram apenas como facilitadores do acesso aos mercados, às informações sobre estes e aos parceiros externos. Tais evidências remetem à Evidência 7 - "A atuação nos mercados externos por intermédio dos agentes de exportação pode tornar as relações da empresa dependentes destes agentes" - no entanto, considerando os níveis de complexidade, pode-se incluir a seguinte ressalva na Evidência: 
Evidência 12: A atuação nos mercados externos por intermédio dos agentes de exportação pode tornar as relações da empresa dependentes destes agentes quando a empresa possui baixo nível de adaptação complexiva.

Desse modo, percebe-se que a Surf Wear se mostrou capaz de se adaptar com maior facilidade ao mercado externo, estabelecendo parcerias diretas com o mercado - que são relações pautadas na confiança que podem reduzir os efeitos da incerteza e do oportunismo. Isso fez com que as relações da empresa com os mercados se tornassem menos dependentes da atuação dos agentes, mesmo que não houvesse conhecimento sobre estes mercados. Por outro lado, no caso da Moda Praia, os efeitos da falta de conhecimento e, consequentemente, da incerteza precisaram ser compensados pelas relações de confiança que os agentes de exportação possuem com os mercados externos.

Assim, pode-se perceber que quanto maior o nível de evolução da complexidade da empresa, menos dependente ela se torna da atuação dos agentes e do seu conhecimento sobre os mercados externos, pois possui um comportamento mais pronto para se adaptar às diversas realidades, independente do nível de conhecimento que possua sobre elas. Desse modo, as evidências apresentadas sugerem que:

Evidência 13: Quanto maior o nível de evolução da complexidade, menos importante será o conhecimento sobre os mercados externos na escolha do modo de atuação.

Espera-se também que as empresas com maior nível de adaptação complexiva sejam mais capazes de reconhecer oportunidades e ameaças nos mercados internacionais. Foi evidenciado que o proprietário da Surf Wear, antes de começar a exportar, já sabia da existência dessas oportunidades, em função das viagens internacionais que realiza todos os anos, seja para identificar as tendências da moda ou tecnologias utilizadas nos processos produtivos. Assim, ele buscou as oportunidades de forma deliberada, enquanto a Moda Praia não sabia da existência das oportunidades de exportação, mas estas surgiram inesperadamente. Assim, evidencia-se que:

Evidência 14: Empresas com nível de adaptação complexiva mais elevado podem ser capazes de identificar mais facilmente as oportunidades $e$ ameaças nos mercados internacionais.
Por fim, sabe-se que o segundo evento crítico para ambas as empresas foi resultado da indicação das suas redes de relacionamentos. Isso demonstra que, nos dois casos, as empresas possuíam relacionamentos nos mercados locais que desempenharam um papel importante para os seus processos de internacionalização.

Entretanto, ainda considerando o fato de que a Moda Praia continua dependente dos agentes de exportação para permanecer atuando nos mercados externos, enquanto a Surf Wear se mostrou capaz de estabelecer parcerias diretas com as empresas localizadas em outros países, é possível evidenciar que:

Evidência 15: Empresas com nível de adaptação complexiva mais elevado conseguem mais facilmente se tornar insiders em redes de negócios localizadas em mercados externos.

Desse modo, percebe-se que alguns aspectos apresentados nas abordagesn teóricas foram confirmados e outros puderam ser complementados.

\section{CONSIDERAÇÕES FINAIS}

Após a análise dos resultados, evidenciou-se que as duas empresas apresentam comportamentos semelhantes quando se trata dos seus processos de exportação, são identificados dois eventos críticos similares com relação ao período em que ocorreram, às influências externas e às características apresentadas pelas empresas. Contudo, uma das empresas interrompeu as atividades de exportação e iniciou atividades de importação, enquanto a outra manteve os mesmos padrões de comportamento adotados desde o início. A empresa que passou a importar modificou aspectos relevantes do seu comportamento, tal como a escolha pelo mercado de atuação, gerando mais dois eventos considerados críticos para o seu processo de internacionalização, que possuem características que podem ser vistas como evolutivas se comparadas às referentes aos primeiros eventos.

Vários comportamentos foram identificados como congruentes com as premissas do Modelo de Uppsala, tal como iniciar a atuação nos mercados externos por intermédio dos agentes independentes. Ainda assim, muitos outros se apresentaram contrários ao que explica o modelo, corroborando críticas que este recebeu por quase quatro décadas, como o fato de as empresas, mesmo após adquirir

Internext | São Paulo, v.12, n. 3, p. 61-76, set./dez. 2017 
conhecimento sobre os mercados externos, não terem aumentado o seu comprometimento com os mesmos ou modificado a sua forma de atuação. A análise dos comportamentos de internacionalização permitiu a identificação de nove (9) evidências, que refutam ou corroboram as premissas do modelo.

Além disso, foi possível perceber que as divergências dos comportamentos das empresas podem estar relacionadas aos seus níveis de adaptação complexiva. Foi possível identificar que as duas empresas analisadas apresentam padrões de comportamentos opostos no que se refere aos níveis de adaptação complexiva. Enquanto a Moda Praia apresenta-se no nível 1 de complexidade, evoluindo para o segundo nível, a Surf Wear demonstra estar no nível 4, evoluindo para o quinto e último nível. Isso demonstra que a Surf Wear é mais pronta para se adaptar aos diversos ambientes, pois a empresa é capaz de aprender coletivamente com as experiências passadas e de usar esse aprendizado para se organizar em resposta aos acontecimentos externos.

A análise dos resultados sugere ainda seis (6) evidências que indicam a existência de algumas associações entre os níveis de adaptação complexiva das empresas e os seus comportamentos de internacionalização, especialmente no que se refere à escolha pelos mercados externos, do modo de atuação, à importância atribuída aos conhecimentos sobre os mercados e sobre os processos, à Distância Psíquica, à relação da empresa com os agentes externos, à capacidade de identificação de oportunidades e ameaças nos mercados externos e à participação das empresas em redes de relacionamentos internacionais.

Proof 15: Companies with a higher complex adaptation level find it easier to become insiders in business networks located in external markets.

\section{REFERÊNCIAS}

- Boulding, K.E. (1956). General Systems Theory - A Skeleton of Science. In: Management science. 2(3), 197208.

- Calof, J. \& Beamish, P. (1995). Adapting to foreign markets: explaining internationalization. International Business Review, 4(2), 115-31. DOI: 10.1016/09695931(95)00001-G.

- Cavusgil, S.T. (1984). Organizational characteristics associated with export activity. Journal of Management
Studies, $\quad 21(1), \quad 3-22 . \quad$ DOI: $\quad$ 10.1111/j.14676486.1984.tb00222.x

- Denzin, N. K. \& Lincoln, Y. S. (2005). Handbook of Qualitative Research. Thousand Oaks: Sage.

- Eriksson, K. et al.. (1997). Experiential knowledge and cost in the internationalization process. Journal of International Business Studies, 28(2), 337-360.

- Havila, V., Johanson, J. \& Thilenius, P. (2004). International business-relationship triads, International Marketing Review, 21(2), 172 - 186. DOI: 10.1108/02651330410531385.

- Hilal, A. \& Hemais, C. A. (2001). Da Escola de Uppsala à Escola Nórdica de Negócios Internacionais: uma Revisão Analítica. In: XXX Encontro Anual da Associação Nacional dos Programas de Pós-Graduação em Administração, Anais..., Rio de Janeiro: ANPAD.

- Johanson, J. \& Wiedersheim-Paul, F. (1975). The internationalization of the firm: Four Swedish cases. Journal of Management Studies, 12(3): 305-322. DOI: 10.1111/j.1467-6486.1975.tb00514.x

- Johanson, J. \& Vahlne J. E. (1977). The internationalization process of the firm: a model of knowledge development and increasing foreign commitments. Journal International Business Studies, v. 8(1), 23-32.

- (2006). Commitment and opportunity development in the internationalization process: A note on the Uppsala internationalization process model. Management International Review, 46(2), 1-14. DOI: 10.1007/s11575-006-0043-4

- (2009). The Uppsala internationalization process model revisited-from liability of foreignness to liability of Outsidership. Journal International Business Studies, 1411-1431. DOI: 10.1057/jibs.2009.24

- Kelly, S. \& Allison, M. A. (1998). The complexity advantage: how the science of complexity can help your business achieve peak performance. New York.

- Matos, K. S. L. \& Vieira, S. L. (2001). Pesquisa educacional: o prazer de conhecer. Fortaleza: UECE.

- Melin, L. (1992). Internationalization as a strategy process. Strategic Management Journal, 13(1), 99-118. DOI: $10.1002 /$ smj.4250130908

- Merriam, S. B. (2009). Qualitative research and case study applications in education. San Francisco: JosseyBass.

- Ministério da Indústria e Comércio Exterior - MDIC. Retirado de: http://www.mdic.gov.br/ Accessed on 20 July 2016.

- Morin, E. E. (2011). Introdução ao pensamento complexo. Lisboa: Instituto Piaget.

- Patton, M. (2001). Qualitative research and evaluation methods. 3. ed. Thousand Oaks: Sage.

- Pettigrew, A. M. (1987). Context and action in transformation of the firm. Journal of Management 
Studies. 24(6), 649-670. DOI: 10.1111/j.14676486.1987.tb00467.x

- Schweizer, R., Vahlne J.E. \& Johanson, J. (2010). Internationalization as an entrepreneurial process. Journal International Entrepreneurship. 8(1), 343-370. DOI: 10.1007/s10843-010-0064-8

- Sousa, L. L; Freitas, L. S. (2012). Mudanças estratégicas e recursos organizacionais: um estudo de caso numa indústria de papéis sanitários. In: VII EGEPE - Encontro de Estudos sobre Empreendedorismo e Gestão e Pequenas Empresas, Florianópolis

- Welch, L. S. \& Luostarinen, R. (1988). Internationalization: Evolution of a concept. Journal of General Management, 17(3), 333-334.

- Wiedersheim-Paul, F., Olson, H.-C., \& Welch, L. S. (1978). Preexport activity: The first step in internationalization. Journal of International Business Studies, 8(1), 47-58.

\section{Sobre os autores}

- Rennaly Alves da Silva - Mestre, aluna de doutorado no PROPAD/UFPE e Professora Adjunto I do curso de Administração da UFPB. Seus principais temas de interesse consistem em Estratégias, Negócios Internacionais, Capacidades Dinâmicas E-mail: rennaly@hotmail.com

- Viviane Santos Salazar - Doutora em Administração pela Universidade Federal de Pernambuco. Professora Adjunto II do Departamento de Hotelaria e Turismo da Universidade Federal de Pernambuco. Seus principais temas de interesse consistem em Estratégia Empresarial, Marketing de Serviços e Comportamento do Consumidor com foco em empresas de hospitalidade. E-mail: viviane_salazar@yahoo.com.br

- Walter Fernando Araújo de Moraes - Doutorado em Management Sciences - University of Manchester Institute of Science and Techonology. Professor Titular Aposentado da Universidade Federal de Pernambuco. Seus principais temas de interesse consistem em Estratégia Empresarial, Estratégia de Internacionalização, Competição, Recursos Competitivos e Desempenho Empresarial. E-mail:wfam1950@gmail.com 


\section{Internationalization process and complex adaptive systems}

Rennaly Alves da Silva ${ }^{A B}$, Viviane Santos Salazar ${ }^{B}$, and Walter Fernando Araújo de Moraes ${ }^{B}$

${ }^{A}$ Federal University of Paraíba, UFPB, João Pessoa, PB, Brazil

${ }^{B}$ Federal University of Pernambuco, UFPE, Bananeiras, PE, Brazil

\section{ARTICLE DETAILS}

\section{Article history:}

Received: March 15, 2017

Reviewed: June 02, 2017

Accepted: October 06, 2017

Available online: November 12, 2017

Double Blind Review System

\section{Scientific Editor}

Diego Pinto

\section{Keywords:}

Uppsala Model

Complex Adaptive Systems

Santa Cruz do Capibaribe

Industrial Districts

\section{ABSTRACT}

This article aims to analyze the characteristics of the internationalization process of companies from the Santa Cruz do Capibaribe clothing hub in Pernambuco, considering the Complex Adaptive Systems approach. The behaviors of two companies towards foreign markets over time are analyzed. The research method is qualitative, with a longitudinal approach, with the strategy being a case study. Semi-structured interviews were conducted, as well as observation and research into their documentation. Data analysis is performed by means of the steady comparison method proposed by Merriam (2009). A cross analysis of cases that generated fifteen (15) pieces of evidence is presented. It is understood that the companies in an internationalization process can be regarded as Complex Adaptive Systems.

(C) 2017 Internext | ESPM. All rights reserved!

Para citar este artigo:

Silva, R. A.; Salazar, V. S.; de Moraes, W. F. A. (2017). Processo de internacionalização e sistemas adaptativos complexos. Internext - Revista Eletrônica de Negócios Internacionais, 12 (3), 61-76. DOI: http://dx.doi.org/10.18568/1980-4865.12361-76

Para acessar este artigo: $h t t p: / / d x . d o i . o r g / 10.18568 / 1980-4865.12361-76$ 